\title{
Assessment of Age-Related Dimensions of the Salivary and Thyroid Glands Using Three-Dimensional Computed Tomography in Children
}

\author{
Se-Hwan Hwang, In-Jun Park, Yeon Min Jeong, Yeon Ji Lee, \\ Jun-Myung Kang, Jae-Hyun Seo, and Young-Hoon Joo \\ Department of Otolaryngology-Head and Neck Surgery, Bucheon St. Mary's Hospital, College of Medicine, \\ The Catholic University of Korea, Bucheon, Korea
}

\section{소아에서 전산화단층촬영의 3 차원 재구성을 통한 침샘과 갑상선의 연령별 변화에 대한 분석}

황세환 · 박인준 · 정연민 · 이연지 · 강준명 · 서재현 · 주영훈

가톨릭대학교 의과대학 부천성모병원 이비인후과학교실

Received June 26, 2015

Revised August 10,2015

Accepted August 11, 2015

Address for correspondence

Young-Hoon Joo, MD, PhD

Department of Otolaryngology-

Head and Neck Surgery,

Bucheon St. Mary's Hospital,

College of Medicine,

The Catholic University of Korea,

327 Sosa-ro, Wonmi-gu,

Bucheon 14647, Korea

Tel $+82-32-340-7207$

Fax $+82-32-340-2674$

E-mail joodoct@catholic.ac.kr
Background and Objectives This study aimed to determine the dimensions of normal salivary and thyroid glands and assess their relationship with respect to age and sex using three-dimensional imaging in children.

Subjects and Method One hundred twenty patients were divided into four age groups: group 1 ( $0-5$ years), group 2 (6-10 years), group 3 (11-15 years), and group 4 (16-20 years). The volume, thickness, width, and length of the each gland were measured.

Results The parotid glands exhibited a growth spurt in group 2 . There were no differences between genders for parameters of the parotid gland in groups 1, 2, and 3 except in group 4 . The length of submandibular gland exhibited a monomodal growth pattern, which increased until 20 -years-of-age. There was a significant difference of volume and thickness between the right and left thyroid gland in all groups.

Conclusion Volume and other parameters of the salivary and thyroid gland increase with age. Korean J Otorhinolaryngol-Head Neck Surg 2016;59(3):214-21

Key Words Child $\cdot$ Computer-assisted image processing $\cdot$ Organ size $\cdot$ Salivary glands Thyroid gland.

\section{Introduction}

The parotid gland (PG) and submandibular gland (SMG) are major salivary glands (that are affected by various diseases including neoplasm, infection, and inflammation. These diseases cause hyperplastic or hypertrophic changes in the salivary glands. ${ }^{1,2)}$ Enlargement of the thyroid gland (TG) results from hormonal or immunological stimulation and inflammatory, proliferative, infiltrative, or metabolic disorders. ${ }^{3)}$ Estimation of the size and volume of these glands provide one element of diagnostic information. ${ }^{4}$
Salivary glands grow from birth to early adulthood in an approximately logarithmic growth pattern. An understanding of how these structures change in aging children is paramount for the differentiation of normal and pathological states. ${ }^{1)}$ In addition, the gender of the patient must be considered for assessing the volume of the TG because the TG is somewhat heavier in women and may be affected by sex hormones. ${ }^{1,5)}$ However, information about the age and sex related change in the normal size of healthy salivary and TGs is lacking.

Computer tomography (CT) scan can successfully identify the PG and show changes that occur with development. ${ }^{6}$ The 
CT scan has been used to quantify the volume of the TG in subjects with enlarged thyroids that are extended substernally and is an easy, reliable, and reproducible method of determining TG volume by three-dimensional (3D) reconstruction, which calculates the thyroid volume by multiplication of the area obtained from manually traced regions of interest on axial slices by the interval thickness. ${ }^{3,6)}$ A previous study reported that CT may be used to quantitatively and qualitatively assess structures of the head and neck, and that the technique is useful in the assessment of structural and functional changes of these structures with aging. Such information can be used as a normative baseline to assess subjects of childhood in the clinical setting who undergo CT imaging, and may be useful to aid investigators involved in aging-related research. ${ }^{6}$ )

The purpose of this study was to calculate the dimensions of normal PG, SMG, and TG, and to evaluate their relationship with respect to age and sex using 3D imaging in Korean children.

\section{Subjects and Method}

The patients were referred to CT examination for various clinical reasons unrelated to the salivary glands and TGs. CT scans of 120 children (64 boys and 56 girls) 0-20-years-ofage were selected among patients. Patient selection criteria for the presented analyses were the following: 1) no salivary gland and TG abnormalities detected in clinical chart review and radiology reports, 2) CT examination with contrast administration, and 3) analyzable data sets without artifact from motion or prior dental procedures. Any patient with a history or clinical evidence of endocrine abnormality, genetic syndrome, growth retardation, or abnormality of the head and neck region was excluded through chart review from the study. In this study, all subjects were divided into four age groups: group 1 ( $0-5$ years), group 2 (6-10 years), group 3 (11-15 years), and group 4 (16-20 years). The average ages and numbers of four groups are shown in Table 1. The Institutional Review Board of our hospital approved the retrospective review of medical records.
Routine neck CT scans were performed using a SOMATOM Volume Zoom ${ }^{\mathrm{TM}}$ apparatus (Siemens, Forchheim, Germany). The technical settings were $120 \mathrm{kV}, 240 \mathrm{~mA}, 3 \mathrm{~mm}$ slice thickness, and 1 second scanning time in spiral mode. The field of view was $215 \times 215 \mathrm{~mm}$, which resulted in a $512 \times 512$ matrix. The doses $(\mathrm{kg} \times 2 \mathrm{~mL})$ of intravenous CT contrast (Iohexol $300 \mathrm{mg} \mathrm{I} / \mathrm{mL})$ were given at a rate $(\mathrm{kg} \times 0.04+0.4 \mathrm{~mL} / \mathrm{sec})$. Prior to obtaining contrast enhanced CT transmission images, a 40 second delay was implemented to decrease contrast density in the major vessels and allow a more uniform distribution of contrast while still permitting adequate visualization of vascular structures. After the scan was performed imaging data were stored in a Digital Imaging and Communication in Medicine file and imported to a personal computer. Using 3D-DOCTOR software (Able Software, Lexington, MA, USA), we reconstructed 3D images designed in accordance with anatomic boundaries (Fig. 1). Window widths and centers were adjusted depending on the type of tissue being examined. Once 3D digital models were constructed, measurements of gland size and shape were obtained.

Measurements of width and thickness of the PG, SMG, and TG were performed at the level of the greatest transverse dimension. After 3D images of the PG, SMG, and TG were reconstructed by segmentation technique, the length of the PG, SMG, and TG, defined as the distance between the most superior and the most inferior points of the PG, SMG, and TG, was measured. The volume of each PG, SMG, and TG were calculated automatically. The isthmus of the TG was not included in these measurements.

Linear measurements and volumes were expressed as an average \pm standard deviation. We evaluated relationships between variables, age, and gender using Pearson correlations and we compared groups of quantitative variables using oneway ANOVA. A $p$-value $<0.05$ was considered statistically significant. All calculations were performed using SPSS software ver. 16.0 (SPSS Inc., Chicago, IL, USA).

Table 1. Average age and case numbers in each group

\begin{tabular}{lcccc}
\hline & Group 1 $(\mathrm{n}=30)$ & Group 2 $(\mathrm{n}=30)$ & Group 3 $(\mathrm{n}=30)$ & Group 4 $(\mathrm{n}=30)$ \\
\hline Gender & & & & \\
$\quad$ Male & 16 & 15 & 18 & 15 \\
$\quad$ Female & 14 & 15 & 12 & 15 \\
Age (years) & $2.7 \pm 1.1$ & $8.0 \pm 1.3$ & $12.9 \pm 1.2$ & $18.0 \pm 1.4$ \\
Computed tomography dose index volume (CTDlvol, mGy) & $11 \pm 1.1$ & $17.4 \pm 2.0$ & $22.0 \pm 5.7$ & $28.0 \pm 4.9$ \\
Dose-length product (DLP, mGycm) & $223.8 \pm 48.3$ & $408 \pm 67.3$ & $553.5 \pm 188.1$ & $768.2 \pm 168.5$ \\
\hline
\end{tabular}



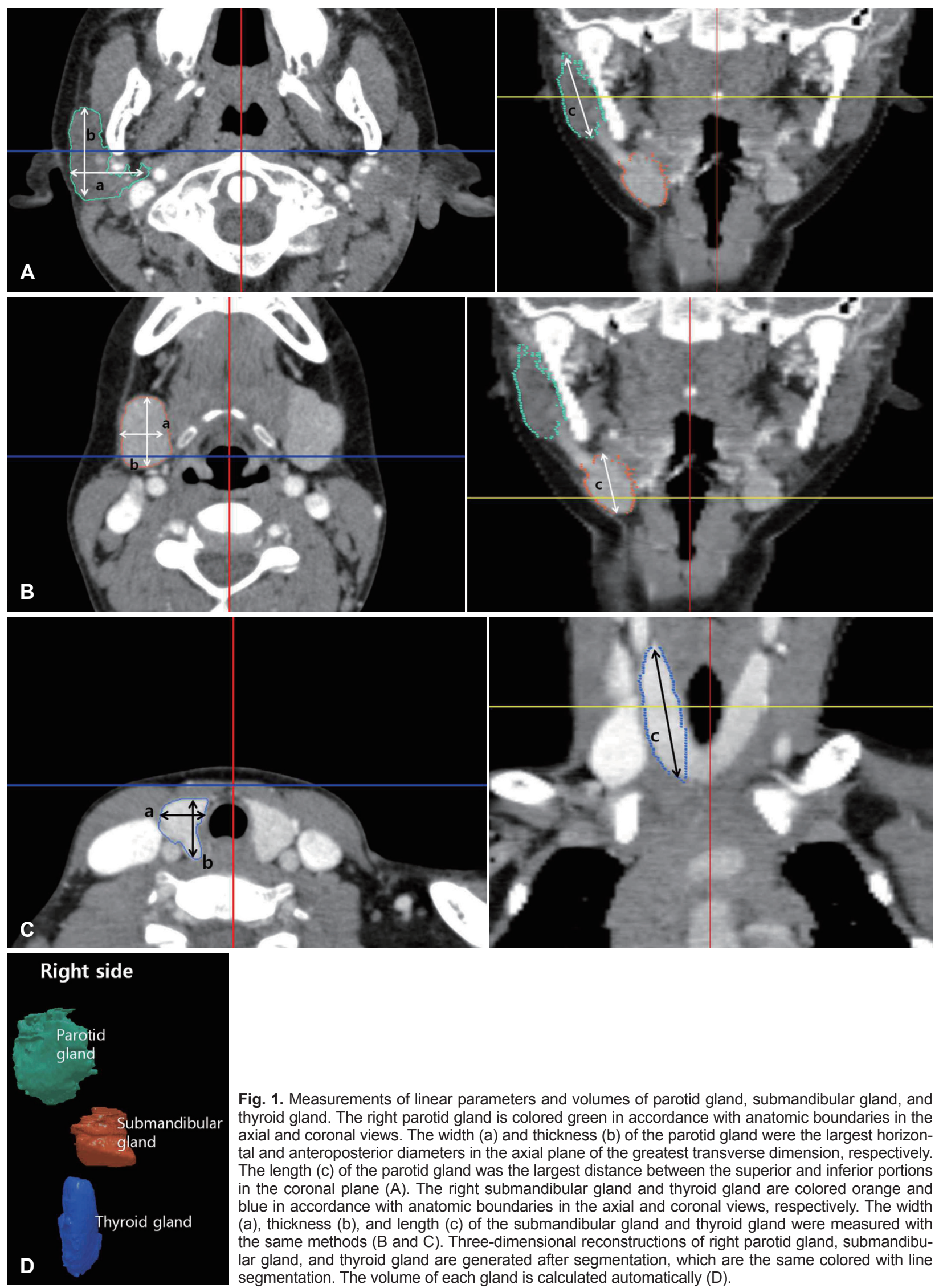

Fig. 1. Measurements of linear parameters and volumes of parotid gland, submandibular gland, and thyroid gland. The right parotid gland is colored green in accordance with anatomic boundaries in the axial and coronal views. The width (a) and thickness (b) of the parotid gland were the largest horizontal and anteroposterior diameters in the axial plane of the greatest transverse dimension, respectively. The length (c) of the parotid gland was the largest distance between the superior and inferior portions in the coronal plane (A). The right submandibular gland and thyroid gland are colored orange and blue in accordance with anatomic boundaries in the axial and coronal views, respectively. The width (a), thickness (b), and length (c) of the submandibular gland and thyroid gland were measured with the same methods ( $B$ and $C$ ). Three-dimensional reconstructions of right parotid gland, submandibular gland, and thyroid gland are generated after segmentation, which are the same colored with line segmentation. The volume of each gland is calculated automatically (D). 


\section{Results}

Volume and size parameters of the PG, SMG, and TG were positively correlated with age $(p<0.05)$ (Table 2$)$. The PGs exhibited a growth spurt of volume between 6 and 10 years of age (group 2) ( $\mathrm{r}=0.65$ for right, $p<0.001 ; \mathrm{r}=0.62$ for left, $p$ $<0.001$ ) (Table 3). There was also close correlation between age and thickness ( $\mathrm{r}=0.48$ for right, $p=0.007 ; \mathrm{r}=0.60$ for left, $p<0.001$ ), width ( $\mathrm{r}=0.57$ for right, $p=0.001 ; \mathrm{r}=0.50$ for left, $p=0.005$ ) of the PG in the group 2. in pediatric groups (groups $1-3)$, only marginal differences were found between genders in the parameters of the PG. However, in group 4, the male volume (right, $p=0.004$; left, $p=0.004$ ), width (right, $p=0.010$; left, $p=0.009$ ), and length (right, $p=0.001$; left, $p=0.001$ ) of the PG were larger than those of females (Table 4). There was a significant increase in the mean volume, thickness, and length of SMG in groups 1 and 2, but this was not found for

Table 2. Correlation of the age with salivary gland volume according to laterality

\begin{tabular}{lcccccc}
\hline & \multicolumn{2}{c}{ Right } & & \multicolumn{2}{c}{ Left } \\
\cline { 2 - 3 } \cline { 5 - 6 } & \multicolumn{2}{c}{$r$} & p value* & & $r$ & p value* \\
\hline PG volume $\left(\mathrm{mm}^{3}\right)$ & 0.756 & $<0.0001$ & & 0.727 & $<0.0001$ \\
SMG volume $\left(\mathrm{mm}^{3}\right)$ & 0.709 & $<0.0001$ & & 0.731 & $<0.0001$ \\
TG volume $\left(\mathrm{mm}^{3}\right)$ & 0.860 & $<0.0001$ & & 0.818 & $<0.0001$ \\
\hline
\end{tabular}

Spearman's correlation. $* p<0.0001 . P G$ : parotid gland, SMG: submandibular gland, TG: thyroid gland the glands of groups 3 and 4. Especially in length, a monomodal growth pattern occurred and increased until 20-years-ofage ( $\mathrm{r}=0.82$ for right, $p<0.001 ; \mathrm{r}=0.80$ for left, $p<0.001$ ).

The TGs exhibited a fastest growth pattern of volume between 0 - and 5-years-of-age (group 1) ( $\mathrm{r}=0.82$ for right, $p<$ $0.001 ; \mathrm{r}=0.82$ for left, $p<0.001)$. A significant linear regression model was found between age and volume, thickness and length of the TGs in the group 1 and 2 (Table 5). There was no significant difference between genders in the mean volume, thickness, width, and length of TGs in all groups except the thickness of the glands of groups 2 (Table 6). In all age groups, volume and thickness of the right thyroid lobe were significantly larger than those of the left lobe $(p<0.05)$ (Table 7). However, there was no significant difference of the width and length between the right and left lobes in the pediatric group.

\section{Discussion}

Various imaging modalities including ultrasonography, CT, and magnetic resonance imaging (MRI) have been used to evaluate the structures of head and neck organs, with some studies comparing changes in structure with age. ${ }^{7)} \mathrm{CT}$ has been established as an accurate means of measuring PG, SMG, and TG volume in both pediatric and adult populations. ${ }^{6,8)} \mathrm{CT}$

Table 3. Results of linear regression analysis between age and measurements of salivary glands

\begin{tabular}{|c|c|c|c|c|c|c|c|c|c|c|c|}
\hline \multirow{2}{*}{ Parameter } & & \multicolumn{2}{|c|}{ Group 1} & \multicolumn{2}{|c|}{ Group 2} & \multicolumn{2}{|c|}{ Group 3} & \multicolumn{2}{|c|}{ Group 4} & \multicolumn{2}{|c|}{ Total } \\
\hline & & $r$ & $p$ value & $r$ & $p$ value & $r$ & $p$ value & $r$ & $p$ value & $r$ & $p$ value \\
\hline \multicolumn{12}{|l|}{ PG } \\
\hline \multirow[t]{2}{*}{ Volume $\left(\mathrm{cm}^{3}\right)$} & $\mathrm{R} t$ & 0.50 & $0.005^{*}$ & 0.65 & $<0.001^{*}$ & 0.28 & 0.129 & 0.20 & 0.280 & 0.75 & $<0.001^{*}$ \\
\hline & $\mathrm{Lt}$ & 0.45 & $0.012^{*}$ & 0.62 & $<0.001^{*}$ & 0.39 & $0.036^{*}$ & 0.06 & 0.750 & 0.73 & $<0.001^{*}$ \\
\hline \multirow[t]{2}{*}{ Thickness (mm) } & Rt & 0.10 & 0.597 & 0.48 & $0.007^{*}$ & 0.06 & 0.772 & 0.21 & 0.260 & 0.38 & $<0.001^{*}$ \\
\hline & $\mathrm{L} \dagger$ & 0.15 & 0.442 & 0.60 & $<0.001^{*}$ & 0.09 & 0.644 & -0.11 & 0.555 & 0.37 & $<0.001^{*}$ \\
\hline \multirow[t]{2}{*}{ Width (mm) } & $\mathrm{R} \dagger$ & 0.13 & 0.510 & 0.57 & $0.001^{*}$ & 0.33 & 0.077 & 0.10 & 0.601 & 0.75 & $<0.001^{*}$ \\
\hline & $\mathrm{L} \dagger$ & 0.09 & 0.656 & 0.50 & $0.005^{*}$ & 0.42 & $0.021^{*}$ & 0.01 & 0.964 & 0.70 & $<0.001^{*}$ \\
\hline \multirow[t]{2}{*}{ Length (mm) } & $\mathrm{R} \dagger$ & 0.41 & $0.026^{*}$ & 0.30 & 0.110 & 0.30 & 0.104 & 0.37 & $0.044^{*}$ & 0.75 & $<0.001^{*}$ \\
\hline & $\mathrm{L} \dagger$ & 0.31 & 0.093 & 0.30 & 0.108 & 0.42 & $0.021^{*}$ & 0.29 & 0.117 & 0.71 & $<0.001^{*}$ \\
\hline \multicolumn{12}{|l|}{ SMG } \\
\hline \multirow[t]{2}{*}{ Volume $\left(\mathrm{cm}^{3}\right)$} & Rt & 0.45 & $0.014^{*}$ & 0.66 & $<0.001^{*}$ & 0.18 & 0.347 & 0.10 & 0.607 & 0.70 & $<0.001^{*}$ \\
\hline & L† & 0.57 & $0.001^{*}$ & 0.62 & $<0.001^{*}$ & 0.24 & 0.208 & 0.10 & 0.590 & 0.74 & $<0.001^{*}$ \\
\hline \multirow[t]{2}{*}{ Thickness (mm) } & Rt & 0.51 & $0.004^{*}$ & 0.83 & $<0.001^{*}$ & -0.10 & 0.592 & -0.04 & 0.839 & 0.75 & $<0.001^{*}$ \\
\hline & $\mathrm{L} \dagger$ & 0.64 & $<0.001^{*}$ & 0.81 & $<0.001^{*}$ & -0.03 & 0.883 & 0.22 & 0.237 & 0.75 & $<0.001^{*}$ \\
\hline \multirow[t]{2}{*}{ Width (mm) } & $\mathrm{R} \dagger$ & 0.26 & 0.166 & -0.12 & 0.543 & -0.05 & 0.806 & 0.23 & 0.215 & 0.22 & $0.018^{*}$ \\
\hline & L† & 0.27 & 0.143 & -0.08 & 0.665 & 0.06 & 0.763 & -0.20 & 0.301 & 0.29 & $0.001^{*}$ \\
\hline \multirow[t]{2}{*}{ Length (mm) } & $\mathrm{R} \dagger$ & 0.61 & $<0.001^{*}$ & 0.54 & $0.002 *$ & 0.38 & $0.041^{*}$ & 0.48 & $0.007^{*}$ & 0.82 & $<0.001^{*}$ \\
\hline & $\mathrm{L} \dagger$ & 0.61 & $<0.001^{*}$ & 0.54 & $0.002^{*}$ & 0.33 & 0.073 & 0.46 & $0.011^{*}$ & 0.80 & $<0.001^{*}$ \\
\hline
\end{tabular}

$* p<0.05$. PG: parotid gland, SMG: submandibular gland 
Korean J Otorhinolaryngol-Head Neck Surg I 2016;59(3):214-21

Table 4. ANOVA results of gender differences in each age group of salivary glands

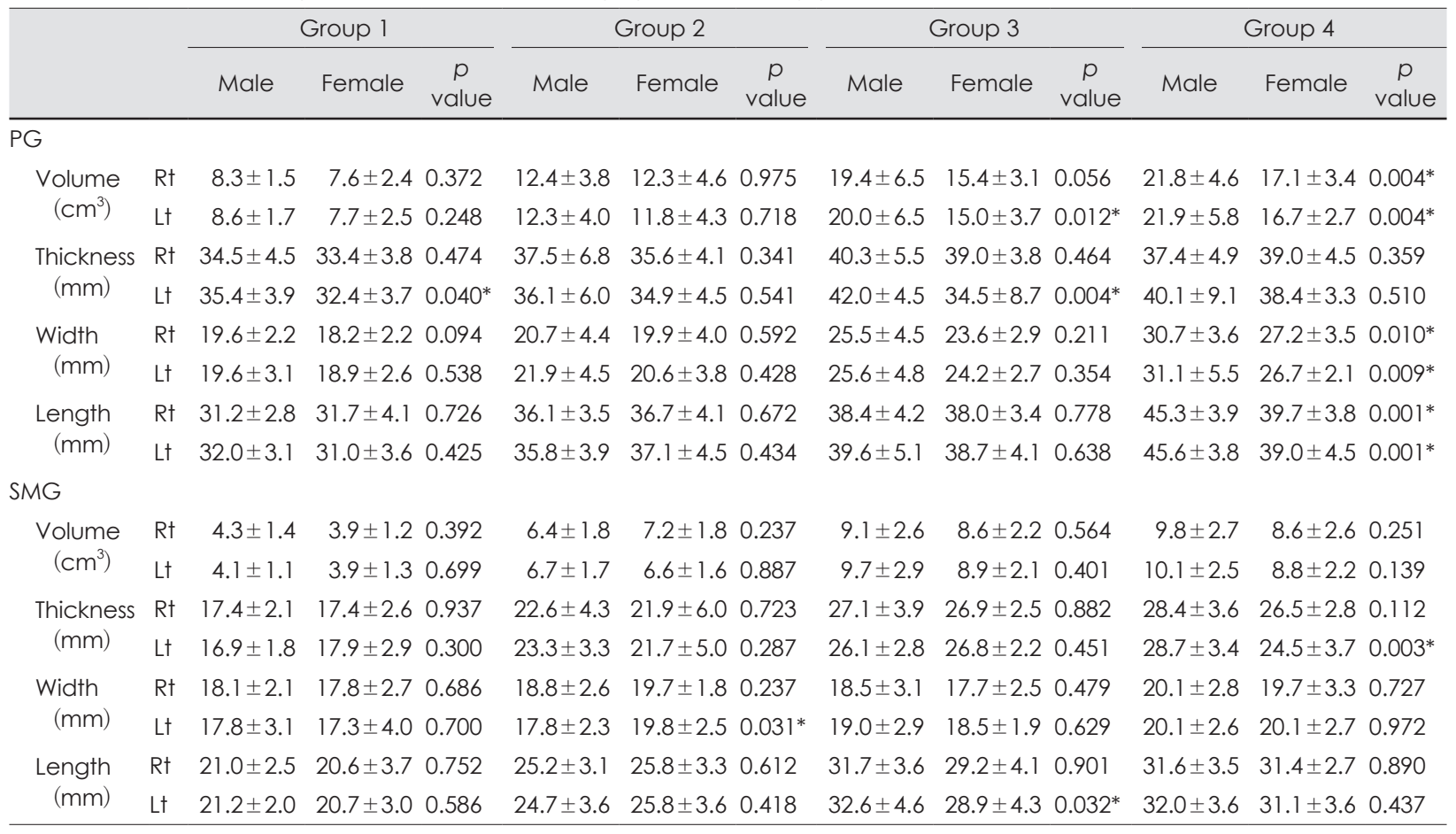

*p<0.05. PG: parotid gland, SMG: submandibular gland

Table 5. Results of linear regression analysis between age and measurements of TG

\begin{tabular}{|c|c|c|c|c|c|c|c|c|c|c|c|}
\hline \multirow{2}{*}{ Parameter } & & \multicolumn{2}{|c|}{ Group 1} & \multicolumn{2}{|c|}{ Group 2} & \multicolumn{2}{|c|}{ Group 3} & \multicolumn{2}{|c|}{ Group 4} & \multicolumn{2}{|c|}{ Total } \\
\hline & & $r$ & $p$ value & $r$ & p value & $r$ & $p$ value & $r$ & $p$ value & $r$ & $p$ value \\
\hline \multicolumn{12}{|l|}{ TG } \\
\hline \multirow[t]{2}{*}{ Volume $\left(\mathrm{cm}^{3}\right)$} & $\mathrm{R} \dagger$ & 0.82 & $<0.001^{*}$ & 0.71 & $<0.001^{*}$ & 0.39 & $0.034^{*}$ & 0.21 & 0.266 & 0.86 & $<0.001^{*}$ \\
\hline & $\mathrm{L} \dagger$ & 0.82 & $<0.001^{*}$ & 0.65 & $<0.001 *$ & 0.32 & 0.090 & 0.09 & 0.628 & 0.82 & $<0.001^{*}$ \\
\hline \multirow[t]{2}{*}{ Thickness (mm) } & $\mathrm{R} \dagger$ & 0.73 & $<0.001^{*}$ & 0.34 & 0.064 & 0.24 & 0.193 & 0.05 & 0.777 & 0.78 & $<0.001^{*}$ \\
\hline & $\mathrm{L} \dagger$ & 0.71 & $<0.001^{*}$ & 0.42 & $0.021^{*}$ & -0.12 & 0.512 & 0.04 & 0.820 & 0.71 & $<0.001^{*}$ \\
\hline \multirow[t]{2}{*}{ Width (mm) } & Rt & 0.34 & 0.064 & 0.23 & 0.214 & 0.29 & 0.122 & 0.00 & 1.000 & 0.70 & $<0.001^{*}$ \\
\hline & $\mathrm{Lt}$ & 0.45 & $0.014^{*}$ & 0.34 & 0.066 & 0.25 & 0.192 & 0.01 & 0.949 & 0.66 & $<0.001^{*}$ \\
\hline \multirow[t]{2}{*}{ Length (mm) } & $\mathrm{R} \dagger$ & 0.71 & $<0.001^{*}$ & 0.74 & $<0.001^{*}$ & 0.26 & 0.171 & 0.16 & 0.389 & 0.90 & $<0.001^{*}$ \\
\hline & $\mathrm{L} \dagger$ & 0.72 & $<0.001^{*}$ & 0.73 & $<0.001^{*}$ & 0.23 & 0.231 & 0.11 & 0.576 & 0.85 & $<0.001^{*}$ \\
\hline
\end{tabular}

*p<0.05. TG: thyroid gland

scan of the neck is a method which is easy to standardize and always permits complete evaluation of the PG, SMG, and TG. In addition, volume measurement by CT scanning is very accurate. ${ }^{8)}$ Since tracing of the thyroid is easy on CT scan based on the difference in density between the TG and adjacent soft tissue, TG volume measurement in CT scans has been used as a calibrated method to calculate the optimal correction factor in sonographic TG volume measurements. ${ }^{8)} \mathrm{CT}$ allows analysis of the parameters including size and volume, which enables an accurate quantitative assessment of various gland diseases. An important consideration in establishing pathologic volumetric change of glands is the potential confounding effect of age. Therefore, we retrospectively studied the normal age-related changes of these glands using CT.

PG and SMG change in size and volume during aging. ${ }^{1,69-11)}$ However, most of these studies evaluated the volume change of mainly adult populations or after radiotherapy, which limits measurement of the dynamic change and normal value of the gland volume in children. In this study, the volume and size parameters of the PG and SMG were measured and their relationship with respect to sex and age were evaluated in the children population.

Previously, it was reported that volumetric age-related tendencies of PG and SMG showed similarities and, from birth 
Table 6. ANOVA results of gender differences in each age group of TG

\begin{tabular}{|c|c|c|c|c|c|c|c|c|c|c|c|c|c|}
\hline & & \multicolumn{3}{|c|}{ Group 1} & \multicolumn{3}{|c|}{ Group 2} & \multicolumn{3}{|c|}{ Group 3} & \multicolumn{3}{|c|}{ Group 4} \\
\hline & & Male & Female & $\begin{array}{c}\mathrm{P} \\
\text { value }\end{array}$ & Male & Female & $\begin{array}{c}\mathrm{p} \\
\text { value }\end{array}$ & Male & Female & $\begin{array}{c}\mathrm{P} \\
\text { value }\end{array}$ & Male & Female & $\begin{array}{c}\mathrm{P} \\
\text { value }\end{array}$ \\
\hline \multicolumn{14}{|l|}{ TG } \\
\hline \multirow{2}{*}{$\begin{array}{l}\text { Volume } \\
\left(\mathrm{cm}^{3}\right)\end{array}$} & R† & $2.0 \pm 1.0$ & $1.9 \pm 0.8$ & 0.795 & $3.9 \pm 0.9$ & $4.2 \pm 1.5$ & 0.411 & $7.3 \pm 2.3$ & $6.5 \pm 1.7$ & 0.269 & $8.8 \pm 2.1$ & $9.1 \pm 3.0$ & 0.804 \\
\hline & Lt & $1.8 \pm 0.9$ & $1.7 \pm 0.8$ & 0.812 & $3.6 \pm 1.0$ & $4.0 \pm 1.5$ & 0.376 & $6.6 \pm 2.0$ & $6.2 \pm 2.2$ & 0.602 & $7.3 \pm 1.3$ & $7.4 \pm 2.8$ & 0.865 \\
\hline \multirow{2}{*}{$\begin{array}{l}\text { Thickness } \\
\text { (mm) }\end{array}$} & Rt & $13.0 \pm 2.1$ & $12.7 \pm 2.4$ & 0.774 & $15.0 \pm 1.6$ & $16.5 \pm 1.5$ & $0.016^{*}$ & $18.2 \pm 2.5$ & $17.0 \pm 1.3$ & 0.151 & $19.0 \pm 1.6$ & $18.7 \pm 2.2$ & 0.744 \\
\hline & $\mathrm{Lt}$ & $11.7 \pm 1.8$ & $11.5 \pm 2.1$ & 0.745 & $13.7 \pm 2.0$ & $15.4 \pm 2.3$ & $0.032^{*}$ & $17.2 \pm 2.7$ & $16.4 \pm 1.7$ & 0.319 & $17.4 \pm 2.2$ & $17.1 \pm 2.3$ & 0.699 \\
\hline \multirow{2}{*}{$\begin{array}{l}\text { Width } \\
(\mathrm{mm})\end{array}$} & R† & $9.2 \pm 1.3$ & $9.4 \pm 1.7$ & 0.647 & $11.5 \pm 1.7$ & $12.0 \pm 1.4$ & 0.343 & $13.0 \pm 2.0$ & $11.8 \pm 2.2$ & 0.128 & $13.9 \pm 2.0$ & $14.5 \pm 2.4$ & 0.460 \\
\hline & $\mathrm{L} \dagger$ & $9.4 \pm 1.4$ & $9.3 \pm 1.2$ & 0.830 & $11.3 \pm 1.5$ & $11.8 \pm 1.9$ & 0.370 & $13.1 \pm 2.1$ & $12.2 \pm 1.9$ & 0.273 & $12.9 \pm 2.0$ & $13.8 \pm 1.9$ & 0.215 \\
\hline \multirow{2}{*}{$\begin{array}{l}\text { Length } \\
(\mathrm{mm})\end{array}$} & R† & $25.9 \pm 4.3$ & $25.2 \pm 4.7$ & 0.656 & $32.7 \pm 3.6$ & $32.4 \pm 5.0$ & 0.868 & $42.0 \pm 5.1$ & $42.1 \pm 5.0$ & 0.953 & $48.0 \pm 4.7$ & $46.2 \pm 4.1$ & 0.270 \\
\hline & $\mathrm{L} \dagger$ & $24.9 \pm 3.6$ & $24.7 \pm 4.7$ & 0.869 & $32.3 \pm 3.3$ & $33.0 \pm 6.0$ & 0.730 & $41.1 \pm 5.8$ & $40.6 \pm 6.8$ & 0.839 & $44.7 \pm 5.3$ & $43.0 \pm 4.4$ & 0.346 \\
\hline
\end{tabular}

$* p<0.05$. TG: thyroid gland

Table 7. ANOVA results of right and left differences in each group of TG

\begin{tabular}{|c|c|c|c|c|c|c|c|c|c|c|c|c|}
\hline & \multicolumn{3}{|c|}{ Group 1} & \multicolumn{3}{|c|}{ Group 2} & \multicolumn{3}{|c|}{ Group 3} & \multicolumn{3}{|c|}{ Group 4} \\
\hline & Right & Left & $\begin{array}{c}\mathrm{P} \\
\text { value }\end{array}$ & Right & Left & $\begin{array}{c}\mathrm{P} \\
\text { value }\end{array}$ & Right & Left & $\begin{array}{c}p \\
\text { value }\end{array}$ & Right & Left & $\begin{array}{c}p \\
\text { value }\end{array}$ \\
\hline \multicolumn{13}{|l|}{ TG } \\
\hline $\begin{array}{l}\text { Volume } \\
\qquad\left(\mathrm{cm}^{3}\right)\end{array}$ & $1.9 \pm 0.9$ & $1.8 \pm 0.8$ & $0.001 *$ & $4.0 \pm 1.2$ & $3.8 \pm 1.2$ & $0.005^{*}$ & $7.0 \pm 2.1$ & $6.4 \pm 2.0$ & $0.006^{*}$ & $8.9 \pm 2.5$ & $7.3 \pm 2.1$ & $<0.001^{*}$ \\
\hline $\begin{array}{l}\text { Thickness } \\
(\mathrm{mm})\end{array}$ & $12.9 \pm 2.2$ & $11.6 \pm 1.9$ & $<0.001^{*}$ & $15.7 \pm 1.7$ & $14.5 \pm 2.3$ & $<0.001^{*}$ & $17.7 \pm 2.1$ & $16.9 \pm 2.4$ & $0.013^{*}$ & $18.8 \pm 1.9$ & $17.2 \pm 2.2$ & $<0.001^{*}$ \\
\hline $\begin{array}{l}\text { Width } \\
(\mathrm{mm})\end{array}$ & $9.3 \pm 1.4$ & $9.4 \pm 1.3$ & 0.754 & $11.7 \pm 1.6$ & $11.5 \pm 1.7$ & 0.405 & $12.5 \pm 2.1$ & $12.7 \pm 2.0$ & 0.460 & $14.2 \pm 2.2$ & $13.3 \pm 2.0$ & $0.032 *$ \\
\hline $\begin{array}{r}\text { Length } \\
(\mathrm{mm})\end{array}$ & $25.6 \pm 4.4$ & $24.8 \pm 4.1$ & 0.065 & $32.5 \pm 4.3$ & $32.6 \pm 4.8$ & 0.770 & $42.0 \pm 5.0$ & $40.9 \pm 6.1$ & 0.140 & $47.1 \pm 4.4$ & $43.9 \pm 4.9$ & $<0.001^{*}$ \\
\hline
\end{tabular}

to early adulthood, both glands grew in size in a consistent manner. ${ }^{1)}$ In our study, volume size parameters of the PG and SMG were positively correlated with age. There was a significant increase in the mean volume of both PG and SMG in children aged $0-10$ years. In addition, two glands exhibited a similar growth spurt of volume in children 6-10-years-of-age. There was no significant difference between genders in the parameters of two glands except that the volume, width, and length of the PG in males 16-20-years-of-age were larger than those in females. The results reflect the fact that, of the major salivary glands, the size of the parotid was positively correlated with the body mass index ${ }^{11)}$ and body mass index gained more rapidly after late childhood for males than for females. ${ }^{12)}$

In previous studies, the mean volumes of PG and SMG in adult were approximately $25 \mathrm{~cm}^{3}$ and $11 \mathrm{~cm}^{3}$, respectively. ${ }^{6,10)}$ These results were larger than those of PG and SMG in children aged 16-20-years-of-age in our study $\left(19.5 \mathrm{~cm}^{3}\right.$ and $\left.9.2 \mathrm{~cm}^{3}\right)$. Considering that volumes of the PG increase with age and volumes of the SMG either remain stable or increased with age based on MRI or CT measurements, ${ }^{1,6)}$ these discrepancies would be caused by the factor that the mean age of cases in previous studies was older than those of our group 4.

In our study, size parameters (width, thickness, and length) of the PG and SMG positively correlated with aging, like the volumetric measurements. Since the evaluation of size parameters of salivary glands were not addressed in previous studies, ${ }^{1,6,9-11)}$ we could not perform the comparative analysis of size parameters for usefulness and difference. However, analyzing the linear regression between age and measurements, the width and length of PG and the thickness and length of SMG showed similar correlation pattern with volumetric measurements, respectively. It would mean that these measurements in a two-dimensional plane could reflect age-related volumetric change well and the thickness of PG and the width of SMG could be affected by more the surrounding anatomic change than aging change.

Taş, et al. ${ }^{13)}$ reported that there was a significant positive correlation between TG volume and age in the $0-16$ year age group. Although previous result was similar with the relationship with TG volume and size parameters and age in our 
study, the volume of the TGs increased at a faster rate in group 1 than in the other groups $(\mathrm{r}=0.82)$. Thyroid hormones regulate cell proliferation and influence directly the linear growth, which may be due to a stimulating effect on DNA synthesis in osteoblasts and other cells. In growth retardation caused by hypothyroidism, hormone replacement therapy leads to an initial catch-up growth spurt. ${ }^{14)}$ Considering these facts, it would be reasonable that the high volume growth rate of the TGs in children 0-5-years-of-age could reflect the first growth spurt well and TG function would be more important in early childhood. By contrast, TGs showed the relatively slow growth rate in group $3(\mathrm{r}=0.39)$ and group $4(\mathrm{r}=0.21)$, which were similar with the result of Brown, et al. ${ }^{15)}$ that thyroid volume increased with age during childhood and adolescence, remained fairly constant in younger adults.

A previous study ${ }^{13)}$ reported TG volumes of $1.8 \mathrm{~cm}^{3}, 2.9$ $\mathrm{cm}^{3}, 3.6 \mathrm{~cm}^{3}, 4.8 \mathrm{~cm}^{3}, 9.6 \mathrm{~cm}^{3}, 12.8 \mathrm{~cm}^{3}$, and $15-16 \mathrm{~cm}^{3}$ in subjects aged $0-2$ years, 3-5 years, 6-8 years, 9-11 years, and 12-14 years, respectively. The difference among the age groups was statistically significant but there was no difference in TG volume of male and female children of the same age groups. In our study, the thyroid volume measured in age groups were $1.9 \mathrm{~cm}^{3}, 4.0 \mathrm{~cm}^{3}, 7.0 \mathrm{~cm}^{3}, 8.9 \mathrm{~cm}^{3}$ in subjects aged $0-5$ years, $6-10$ years, $11-15$ years, and $16-20$ years. The difference among these groups was statistically significant. Although the age groups in our study did not completely match with those in the previous study, the TG volume in two studies was similar in early age groups, but TG volume in the previous study was larger than those in our study in late age groups. This discrepancy would result from the difference of ethnicity, which was similar with previous results that the TG volume in Chinese adult was approximately $7.7 \mathrm{~mL}$ compared with $11 \mathrm{~mL}$ in Caucasians. ${ }^{16,17)}$ However, like the previous study, there was no difference in TG volume of male and female children of the same age groups. Presently, the right thyroid lobe volume and thickness in all age group was greater than the left with a significant statistical difference. This finding agrees with previous adult studies done among Chinese and Caucasian subjects. ${ }^{16,17)}$ This finding could show that only comparison between the two sides would not give adequate diagnostic information.

This study had several limitations. The study was retrospective and involved subjects from a patient population rather than from a healthy volunteer. Therefore, not all studied subjects are completely healthy. Nevertheless, we used data from patients with no salivary gland abnormalities, based on clini- cal chart review and radiology reports, and we believe the results approximate that of a normal population. Second, we could not obtain height and weight information in the majority of subjects. Previous studies have suggested that there may be body surface area and body mass index-related differences in salivary and TG volume and size parameters. ${ }^{4,11,13)}$ Height and weight comparisons were not studied because of insufficient previous records. Third, small nodules less than $1 \mathrm{~cm}$ would be difficult to characterize on CT. However, the advancement in technology including improved resolution and thinner slice collimation has led to a particularly dramatic rise in the accuracy of diagnosing the thyroid lesion measuring less than $10 \mathrm{~mm}$ in diameter. There were the significant associations between lesion number, size, and consistency on CT and benignity as determined by US. ${ }^{18)}$ Despite these limitations, we believe that our data provide useful information for those interested in studying changes in the salivary and TGs with normal aging in children, and provide a basic methodological approach for future study of normal structural and functional changes in this region with aging.

In conclusion, the results provide a basis for objective normal dimension of salivary and TG development with 3D reconstruction CT. Volume and other parameters of the PG, SMG, and TG increased with age. Significant sex dimorphism in the volume, width, and length of the PG was evident in group 4. Length of the SMG correlated with increasing age until 20-years-of-age. Volume and thickness of the right thyroid lobe were significantly larger than those of the left lobe. An understanding of normal 3D salivary and TG anatomy and growth may assist in diagnosis and treatment planning for children with salivary and TG disease.

\section{REFERENCES}

1) Saito N, Sakai O, Bauer CM, Norbash AM, Jara H. Age-related relaxovolumetric quantitative magnetic resonance imaging of the major salivary glands. J Comput Assist Tomogr 2013;37(2):272-8.

2) Ericson S, Hedin M. A clinical roentgenologic method of calculating the volume of the parotid gland. Oral Surg Oral Med Oral Pathol 1970;29(4):536-43.

3) Hermans R, Bouillon R, Laga K, Delaere PR, Foer BD, Marchal G, et al. Estimation of thyroid gland volume by spiral computed tomography. Eur Radiol 1997;7(2):214-6.

4) Ueda D. Normal volume of the thyroid gland in children. J Clin Ultrasound 1990;18(6):455-62.

5) Ghervan C. Thyroid and parathyroid ultrasound. Med Ultrason 2011; 13(1):80-4.

6) Mahne A, El-Haddad G, Alavi A, Houseni M, Moonis G, Mong A, et al. Assessment of age-related morphological and functional changes of selected structures of the head and neck by computed tomography, magnetic resonance imaging, and positron emission tomography. Semin Nucl Med 2007;37(2):88-102. 
7) Chang CY, Hong YC, Chung PC, Tseng CH. A neural network for thyroid segmentation and volume estimation in $\mathrm{CT}$ images. IEEE Comput Intell Mag 2011;6,(4):43-55.

8) Shabana W, Peeters E, De Maeseneer M. Measuring thyroid gland volume: should we change the correction factor? AJR Am J Roentgenol 2006;186(1):234-6.

9) Deasy JO, Moiseenko V, Marks L, Chao KS, Nam J, Eisbruch A. Radiotherapy dose-volume effects on salivary gland function. Int $\mathrm{J}$ Radiat Oncol Biol Phys 2010;76(3 Suppl):S58-63.

10) Medbery R, Yousem DM, Needham MF, Kligerman MM. Variation in parotid gland size, configuration, and anatomic relations. Radiother Oncol 2000;54(1):87-9.

11) Heo MS, Lee SC, Lee SS, Choi HM, Choi SC, Park TW. Quantitative analysis of normal major salivary glands using computed tomography. Oral Surg Oral Med Oral Pathol Oral Radiol Endod 2001;92(2):240-4.

12) Li L, Hardy R, Kuh D, Lo Conte R, Power C. Child-to-adult body mass index and height trajectories: a comparison of 2 British birth cohorts.
Am J Epidemiol 2008;168(9):1008-15.

13) Taş F, Bulut S, Eğilmez H, Oztoprak I, Ergür AT, Candan F. Normal thyroid volume by ultrasonography in healthy children. Ann Trop Paediatr 2002;22(4):375-9.

14) Tarım Ö. Thyroid hormones and growth in health and disease. J Clin Res Pediatr Endocrinol 2011;3(2):51-5.

15) Brown RA, Al-Moussa M, Beck J. Histometry of normal thyroid in man. J Clin Pathol 1986;39(5):475-82.

16) Hsiao YL, Chang TC. Ultrasound evaluation of thyroid abnormalities and volume in Chinese adults without palpable thyroid glands. J Formos Med Assoc 1994;93(2):140-4.

17) Langer P. Normal thyroid size versus goiter--postmortem thyroid weight and ultrasonographic volumetry versus physical examination. Endocrinol Exp 1989;23(2):67-76.

18) Lee C, Chalmers B, Treister D, Adhya S, Godwin B, Ji L, et al. Thyroid lesions visualized on CT: sonographic and pathologic correlation. Acad Radiol 2015;22(2):203-9. 